Supplement of Geosci. Model Dev., 13, 6165-6200, 2020

https://doi.org/10.5194/gmd-13-6165-2020-supplement

(C) Author(s) 2020. This work is distributed under

the Creative Commons Attribution 4.0 License.

(c) (1)

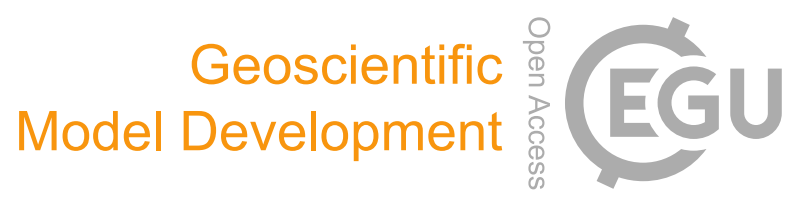

Supplement of

\title{
Overview of the Norwegian Earth System Model (NorESM2) and key climate response of CMIP6 DECK, historical, and scenario simulations
}

Øyvind Seland et al.

Correspondence to: Øyvind Seland (oyvindse@met.no)

The copyright of individual parts of the supplement might differ from the CC BY 4.0 License. 

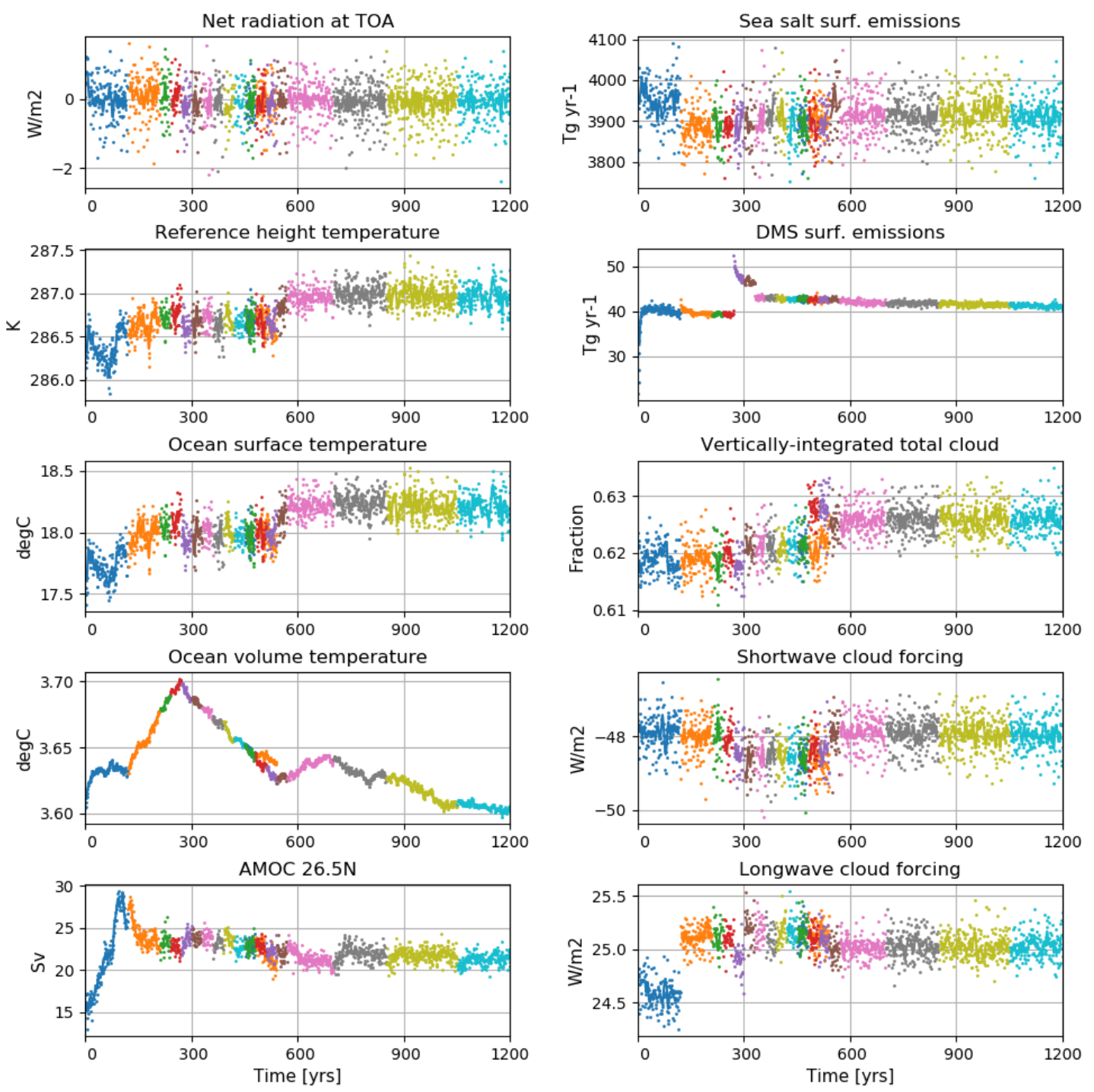

Figure S1. Time evolution of the spin-up of different quantities for NorESM2-MM. Left column (from top to bottom): global and annual means of net radiation at the top of model, surface $(2 \mathrm{~m}$ ) air temperature, sea surface temperature (SST), global and volume averaged ocean temperature, and Atlantic meridional overturning circulation (AMOC) at $26.5^{\circ} \mathrm{N}$. Right column (from top to bottom): global and annual sum of sea salt surface emissions, DMS (dimethylsulfide) surface emissions, global and annual means of vertically-integrated total cloud cover, shortwave cloud forcing and longwave cloud forcing. 

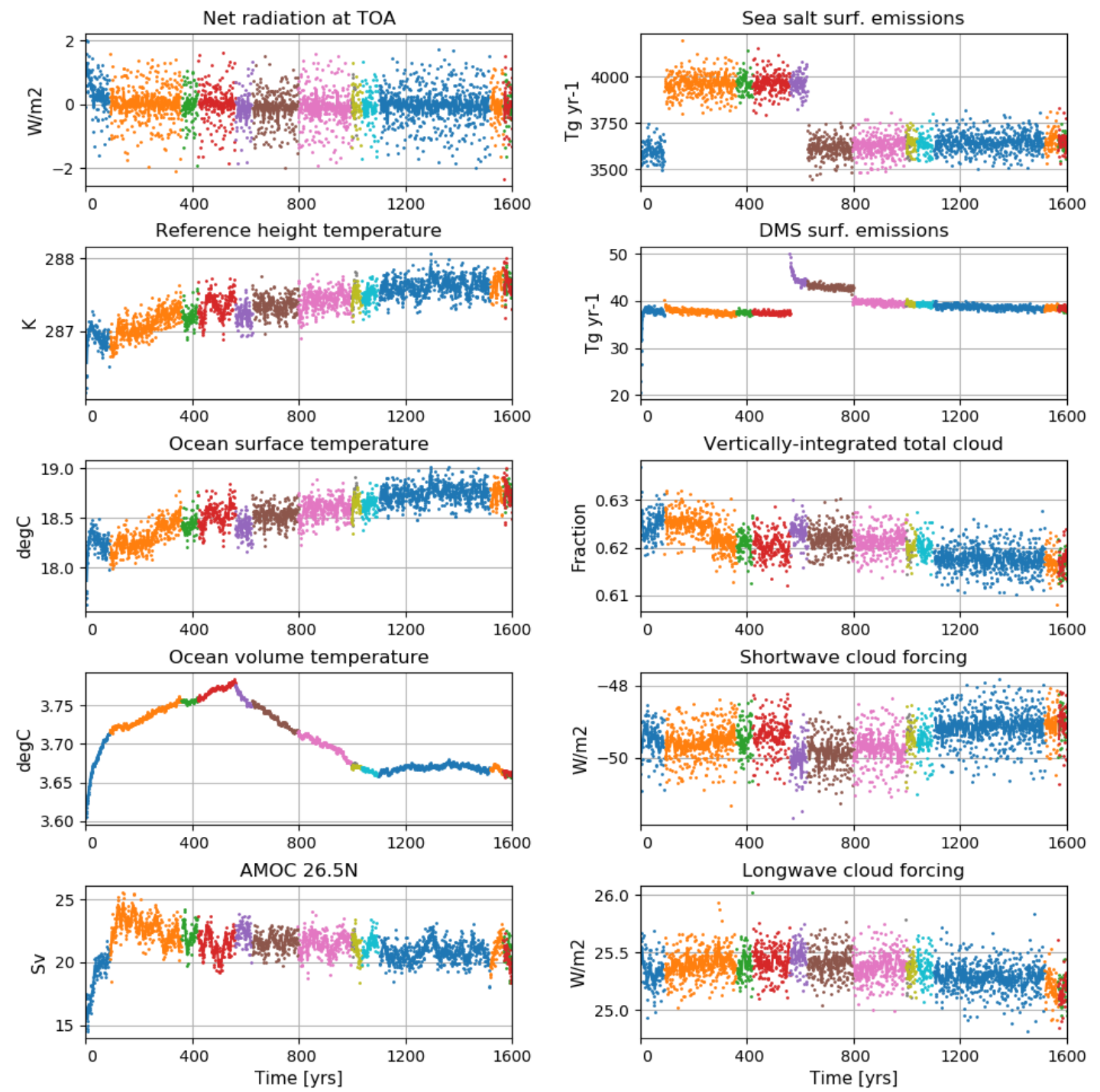

Figure S2. As in Fig. S1, but for NorESM2-LM. 
(a) Aerosol optical depth $(550 \mathrm{~nm})$

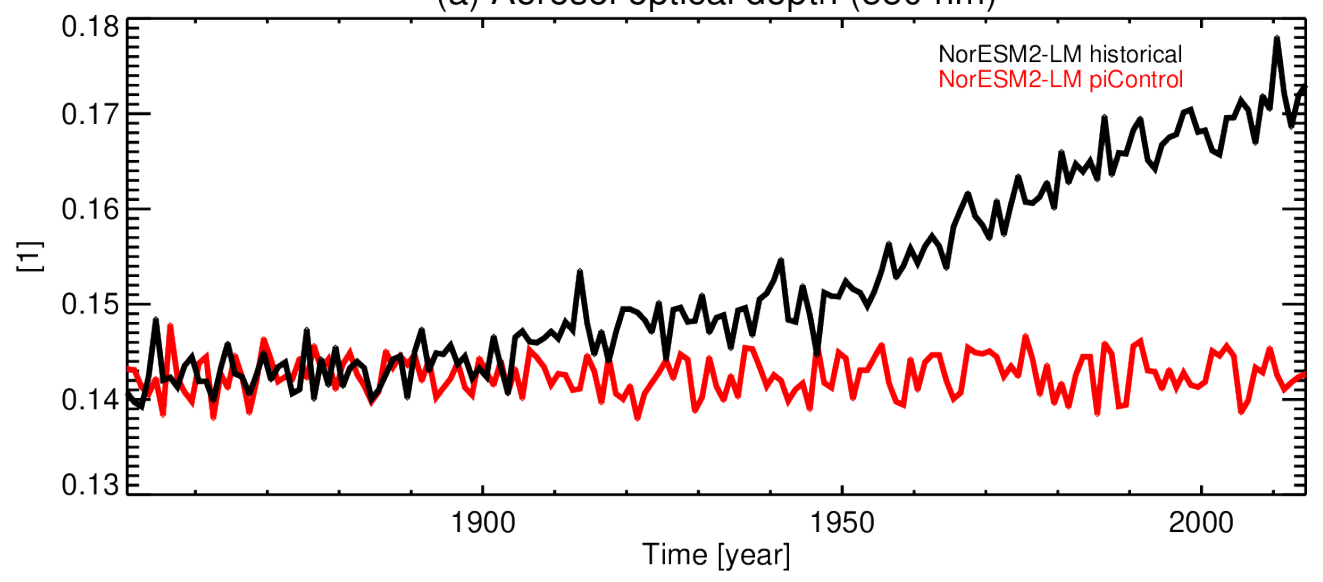

(b) Net downward SW+LW flux (TOA)

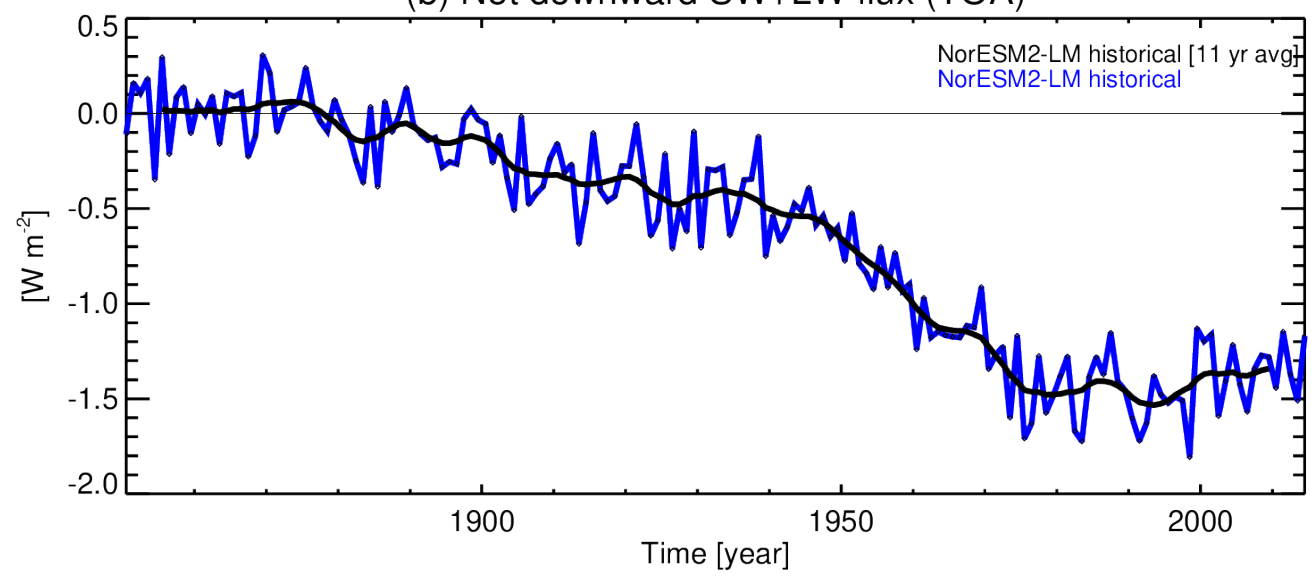

Figure S3. (a) Time evolution of global-mean aerosol optical depth (a) in the pre-industrial control (red) and historical (member 1, black) of NorESM2-LM. (b) Time series of global mean effective radiative forcing (ERF), calculated as the TOA radiative imbalance in the ensemble mean (3 members) of AMIP simulations where only anthropogenic aerosol emissions follow the historical evolution. 


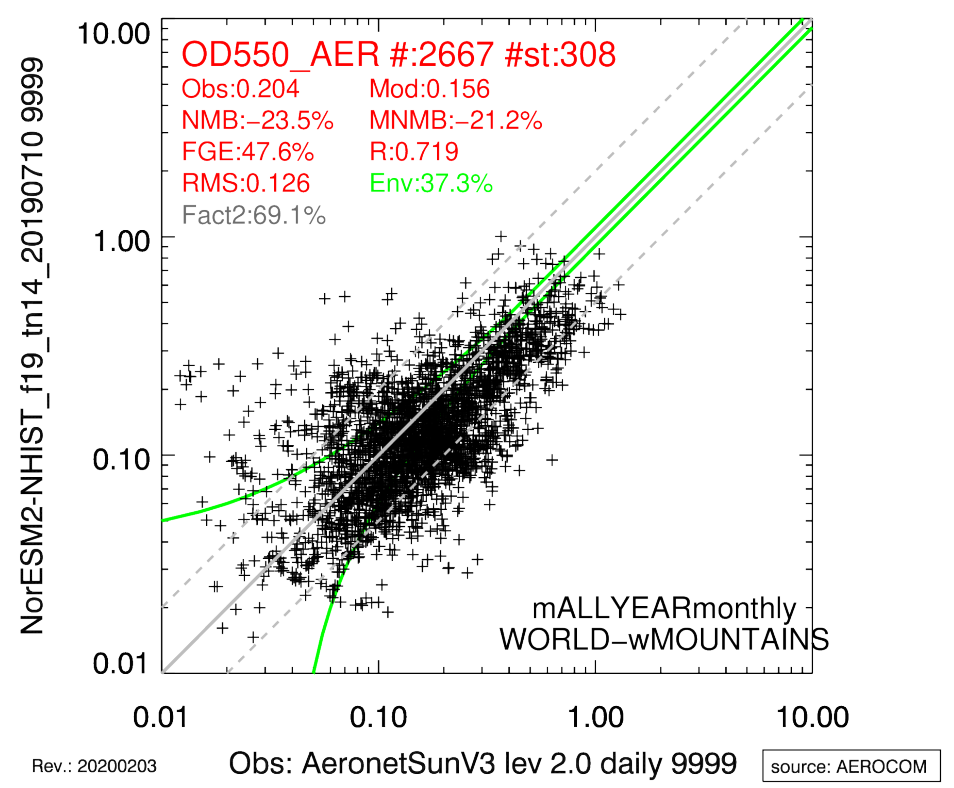

Figure S4. Comparison of aerosol optical depth (at $550 \mathrm{~nm}$ ) in the historical NorESM2-LM simulation (member 1) with Aeronet (Holben et al., 1998) observations. The data from the model and the observations cover the 2005-2014 period. 

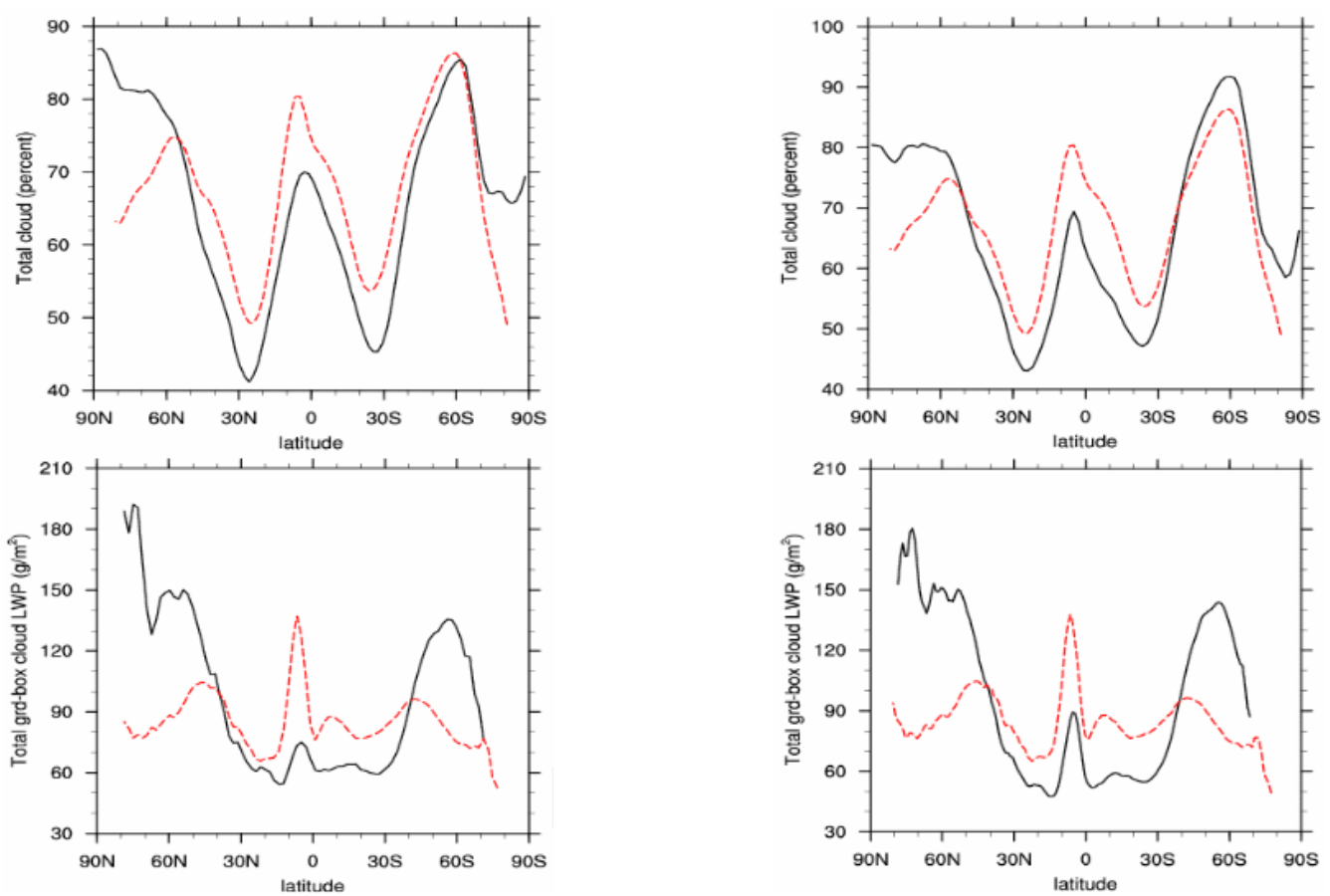

Figure S5. Evaluation of cloud cover and liquid water path (LWP) from NorESM2-MM (left column) and NorESM2-LM (right column). Solid black lines show model fields for the 1980-2009 period. Dashed red lines show observational estimates of annual-mean cloud cover from CLOUDSAT (upper panels) and annual-mean oceanic LWP (O’Dell et al., 2008; bottom panels) 

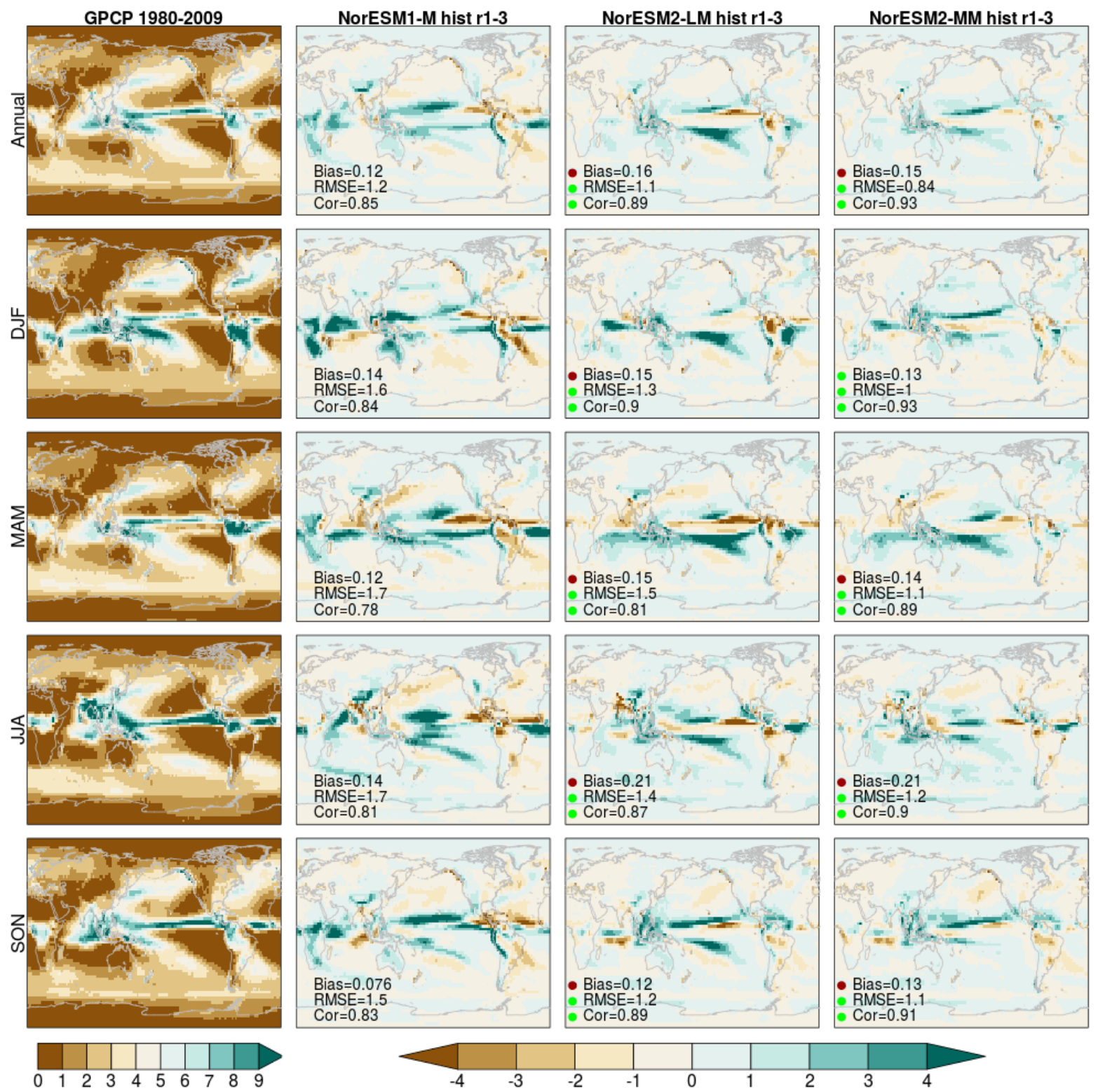

Figure S6. Annual and seasonal total precipitation rate climatology from GPCP (column 1) and biases with respect to GPCP for NorESM1M (column 2), NorESM2-LM (column 3), and NorESM2-MM (column 4). The time period is 1980-2009 and all available members from the historical simulations are used (3 for each of NorESM1-M, NorESM2-LM, and NorESM2-MM). For the bias plots, the following globalmean metrics are shown in the bottom left corner of each panel: bias, RMSE (lower is better), and spatial correlation (Cor; higher is better). For NorESM2-LM and NorESM2-MM, green/red dots are shown on the left side of these metrics and indicate whether the NorESM2 results are better (green) or worse (red) than NorESM1-M. Units are $\mathrm{mm} \mathrm{day}^{-1}$. 

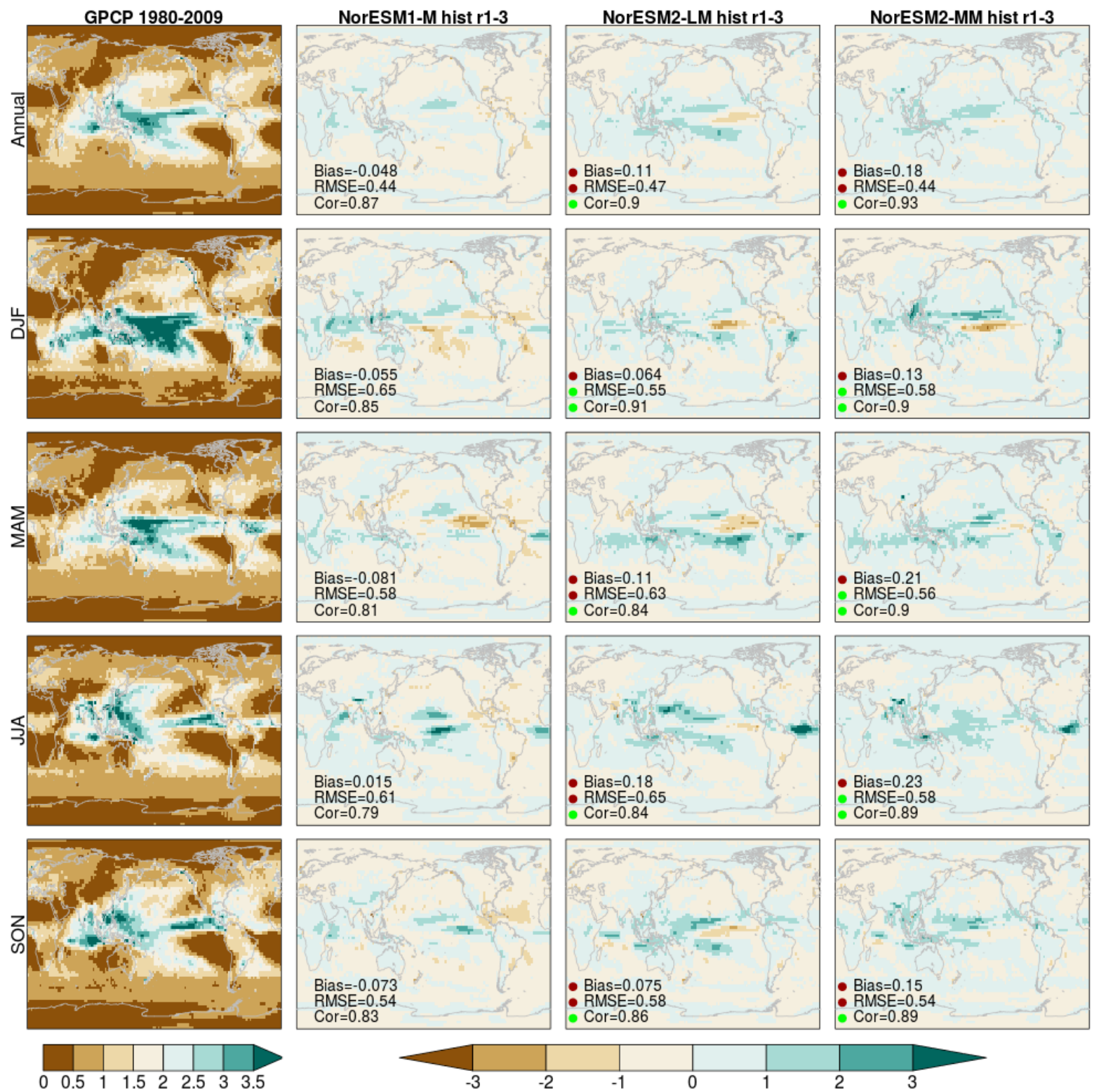

- RMSE $=0.54$

Cor $=0.89$

Figure S7. As in Fig. S6, but for the inter-annual variability (IAV) of the total precipitation rate. The IAV is defined as the standard deviation of the timeseries in each grid point. 
(a)

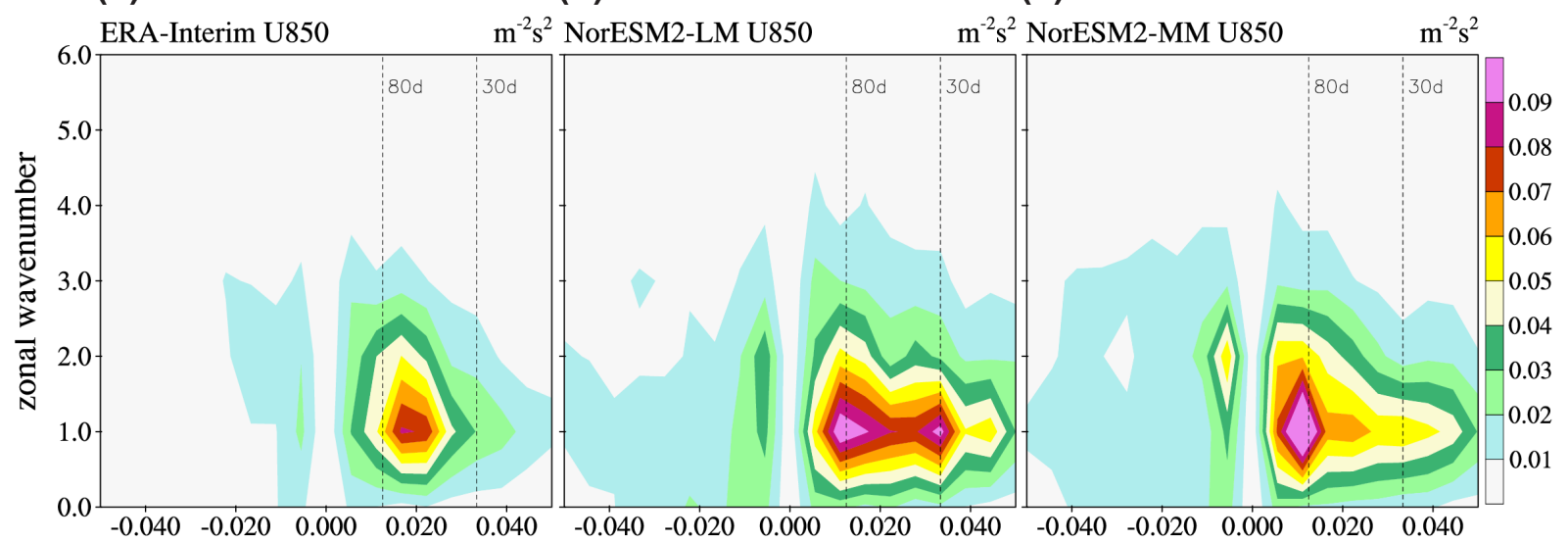

(d)

(e)

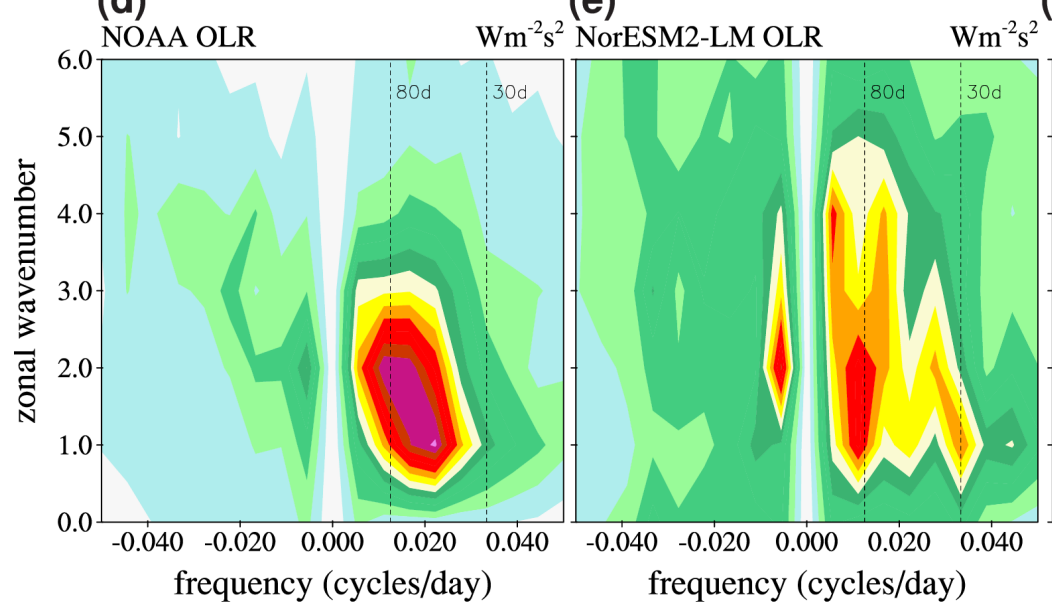

(f)

NorESM2-MM OLR $\quad \mathrm{Wm}^{-2} \mathrm{~s}^{2}$

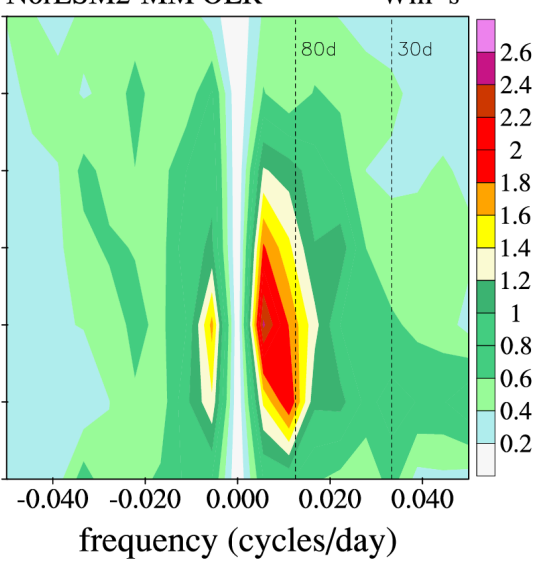

Figure S8. Wavenumber-frequency spectra for the extended winter season (November - April) for the latitude band $10^{\circ} \mathrm{S}$ to $10^{\circ} \mathrm{N}$ for NorESM2-LM and NorESM2-MM. The spectra are computed from daily zonal winds at 850 hPa (U850) using data from (a) ERA-Interim and (b-c) NorESM, and from daily outgoing longwave radiation (OLR) using data from NOAA (d), and NorESM (e-f). The climatological daily cycle was removed prior to computing the spectra. The model data is taken from the first CMIP6 historical member for NorESM2-LM and NorESM2-MM for years 1980-2009, and for years 1979-2008 for ERA-Interim and NOAA. This diagnostic was developed by the USCLIVAR MJO working group and plotted using a script from the NCAR Command Language (NCL) examples that perform the US-CLIVAR diagnostics (https://www.ncl.ucar.edu/Applications/mjoclivar.shtml; Waliser et al., 2009; Ahn et al., 2017). 

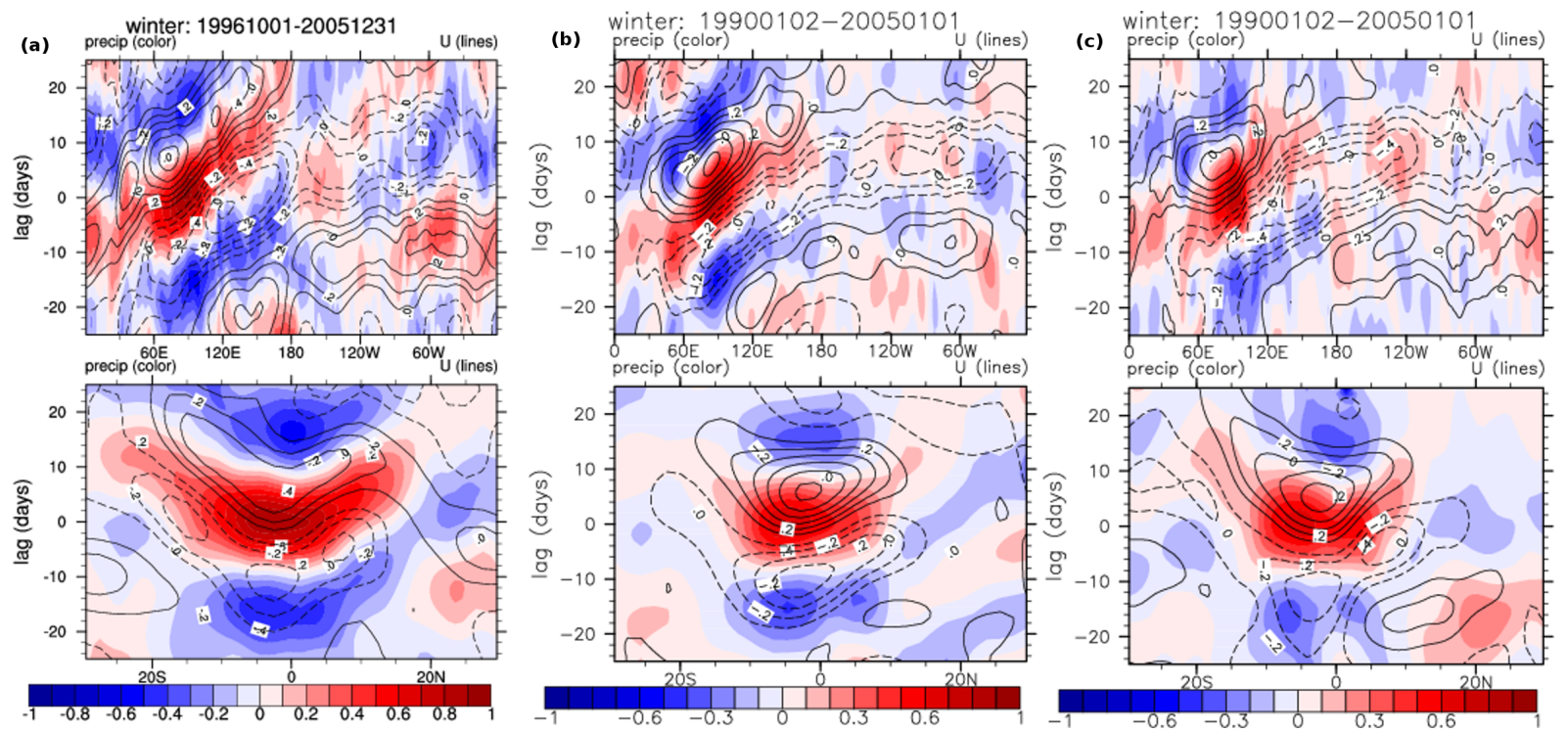

Figure S9. Lead-lag correlations during the extended winter season (November - April) for the latitude band $10^{\circ} \mathrm{S}$ to $10^{\circ} \mathrm{N}$ for observations, NorESM2-MM, and NorESM2-LM. The correlations are computed from daily-mean precipitation and zonal winds at $850 \mathrm{hPa}$ (U850) using data from (a) ERA-Interim, (b) NorESM2-MM, and (c) NorESM2-LM. The climatological daily cycle was removed prior to computing the spectra. The ERA-Interim is taken for the years 1996-2005. The model data is taken from the first CMIP6 historical member for NorESM2-MM and NorESM2-LM for years 1990-2005. This diagnostic was developed by the US-CLIVAR MJO working group and plotted using a script from the NCAR Command Language (NCL) examples that perform the US-CLIVAR diagnostics (https://www.ncl.ucar.edu/Applications/mjoclivar.shtml; Waliser et al., 2009; Ahn et al., 2017). 
(a)
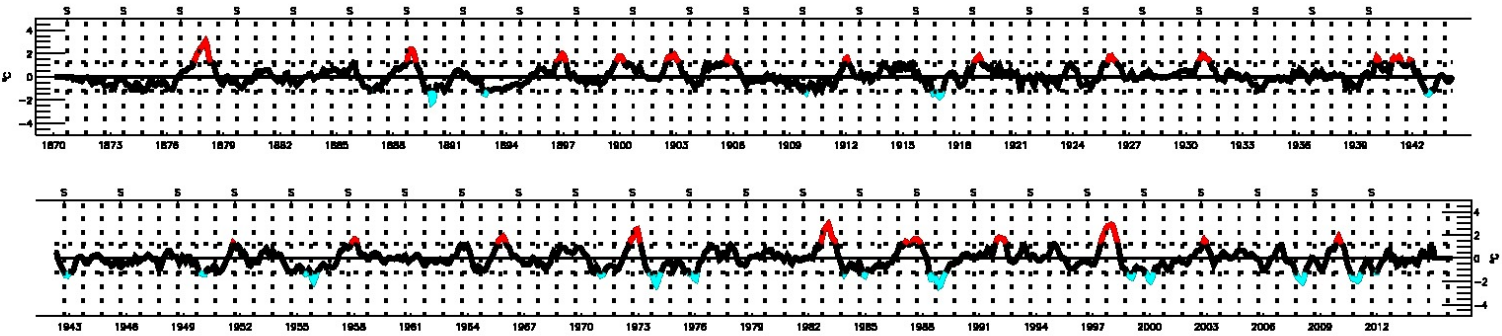

(b)

NINO3.4 (3.8S-3.8N), fO9 PI-CTL,

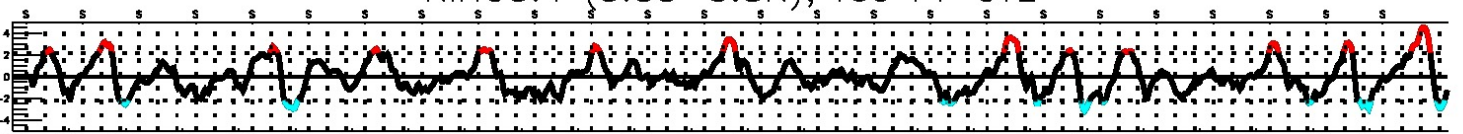

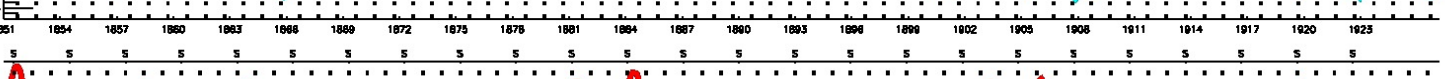

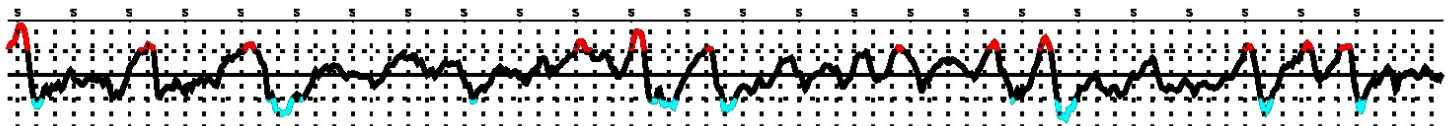
$+\cdots+\cdots+\cdots+\cdots+\cdots$

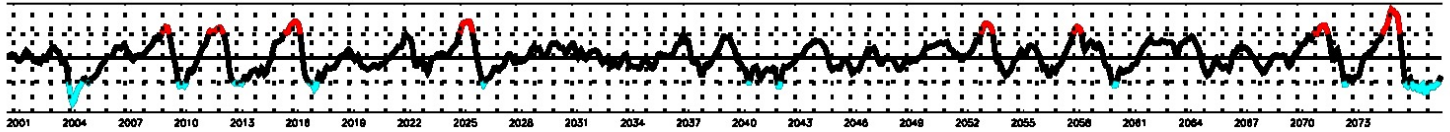

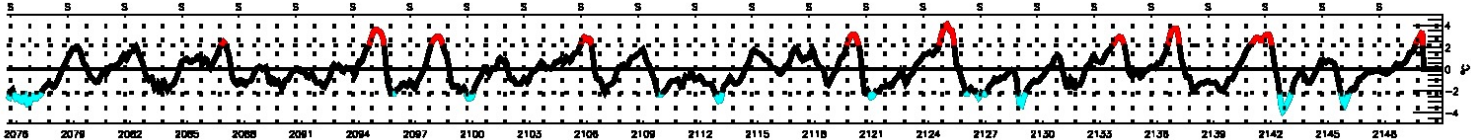

(c) NINO3.4 (3.8S-3.8N), f19 PI-CTL

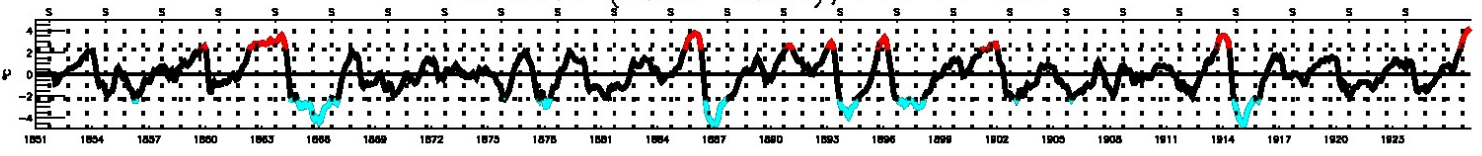

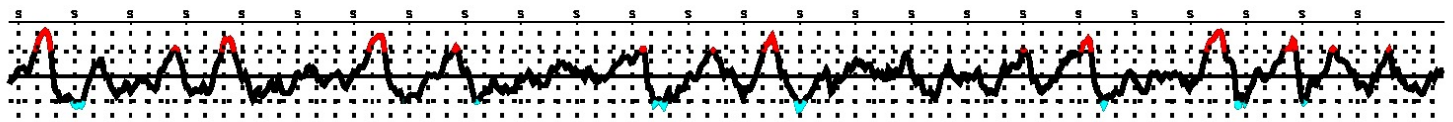
$+\cdots$

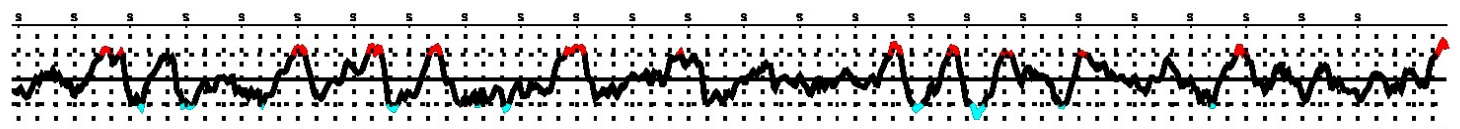
$m-\cdots \cdots \cdots \cdots \cdots \cdots \cdots$

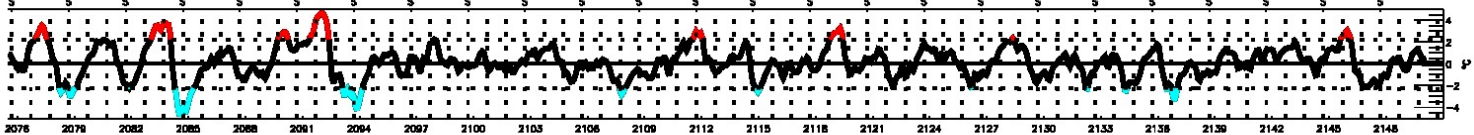

Figure S10. Time evolution of NINO3.4 index anomalies, in observations (panel a; HadISST v1.1; Rayner et al., 2003) and pre-industrial control experiments from NorESM2-MM (panel b) and NorESM2-LM (panel c). Anomalies above 1.5 standard deviations of the respective time-series are marked in red colour, anomalies less than -1.5 standard deviations are marked in cyan colour. 


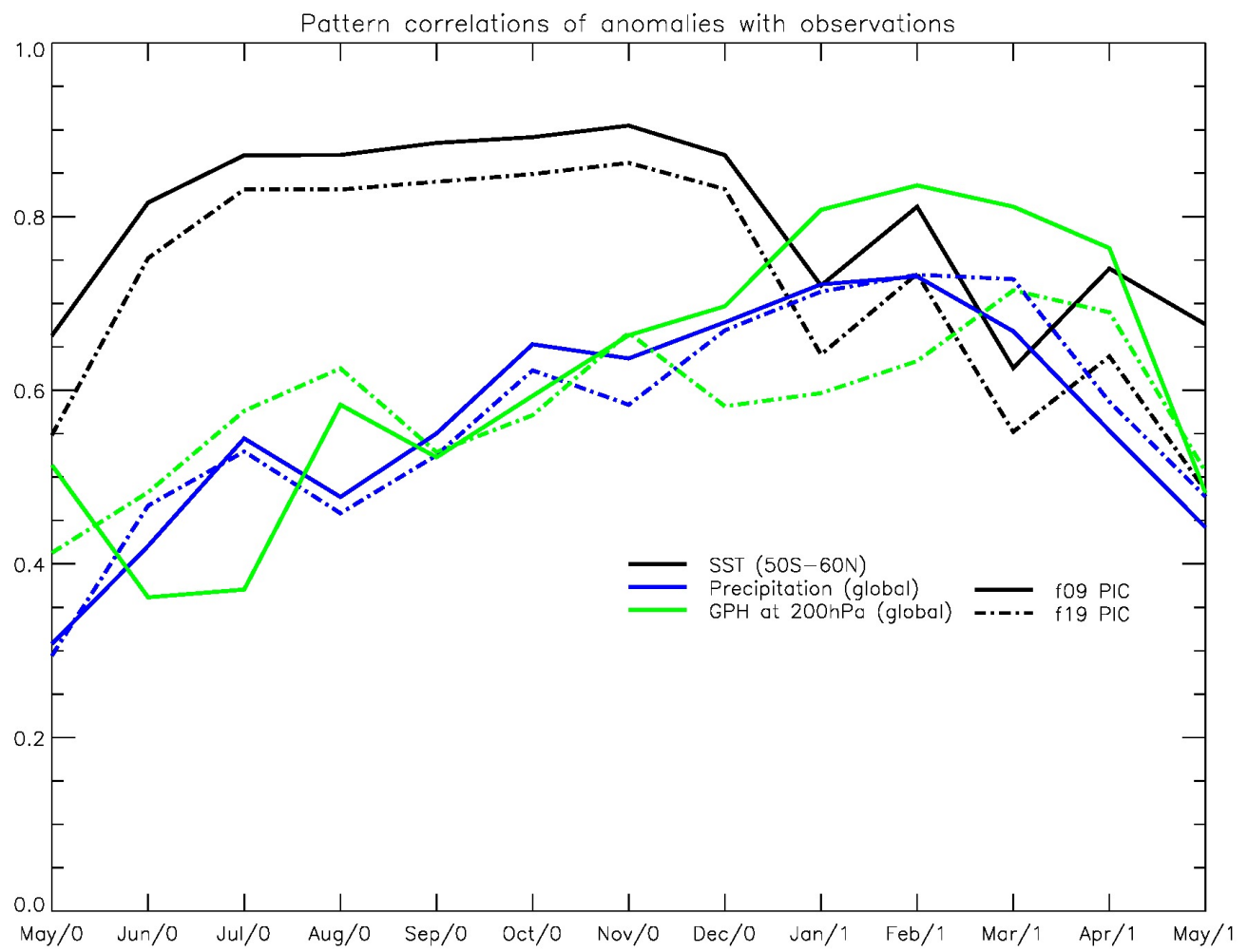

Figure S11. Pattern correlations between model simulations and observations of El-Niño monthly-mean composite anomalies in SST, precipitation and $200 \mathrm{hPa}$ geopotential height. The patterns are computed from observations and model simulations as in Fig. 23, but month by month over the composite El-Niño event, and the correlations between the resulting simulated and observed patterns are calculated. Observations are interpolated onto the relevant model grid in each case. 


\section{References}

Ahn, M.-S., Kim, D., Sperber, K. R., Kang, I.-S., Maloney, E., Waliser, D., and Hendon, H.: MJO simulation in CMIP5 climate models: MJO skill metrics and process-oriented diagnosis, Climate Dynamics, 49, 4023-4045, https://doi.org/10.1007/s00382-017-3558-4, 2017.

Holben, B. N., Eck, T. F., Slutsker, I., Tanre, D., Buis, J. P., Setzer, A., Vermote, E., Reagan, J. A., Kaufman, Y., Nakajima, T., Lavenu, F., Jankowiak, I., and Smirnov, A.: AERONET - A federated instrument network and data archive for aerosol characterization, Remote Sens. Environ., pp. 1-16, 1998.

O’Dell, C. W., Wentz, F. J., and Bennartz, R.: Cloud Liquid Water Path from Satellite-Based Passive Microwave Observations: A New Climatology over the Global Oceans, Journal of Climate, 21, 1721-1739, https://doi.org/10.1175/2007JCLI1958.1, 2008.

Rayner, N. A., Parker, D. E., Horton, E. B., Folland, C. K., Alexander, L. V., Rowell, D. P., Kent, E. C., and Kaplan, A.: Global analyses of sea surface temperature, sea ice, and night marine air temperature since the late nineteenth century, Journal of Geophysical Research: Atmospheres, 108, https://doi.org/10.1029/2002JD002670, https://agupubs.onlinelibrary.wiley.com/doi/abs/10.1029/2002JD002670, 2003.

Waliser, D., Sperber, K., Hendon, H., Kim, D., Wheeler, M., Weickmann, K., Zhang, C., Donner, L., Gottschalck, J., Higgins, W., Kang, I. S., Legler, D., Moncrieff, M., Vitart, F., Wang, B., Wang, W., Woolnough, S., Maloney, E., Schubert, S., and Stern, W.: MJO Simulation Diagnostics, Journal of Climate, 22, 3006-3030, https://doi.org/10.1175/2008JCLI2731.1, https://doi.org/10.1175/2008JCLI2731.1, 2009. 